\title{
Gain in polycrystalline Nd-doped alumina: leveraging length scales to create a new class of high-energy, short pulse, tunable laser materials
}

Elias H. Penilla ${ }^{1,2}$, Luis F. Devia-Cruz, Matthew A. Duarte ${ }^{1,2}$, Corey L. Hardin ${ }^{1}$, Yasuhiro Kodera ${ }^{1,2}$ and Javier E. Garay ${ }^{1,2}$

\begin{abstract}
Traditionally accepted design paradigms dictate that only optically isotropic (cubic) crystal structures with high equilibrium solubilities of optically active ions are suitable for polycrystalline laser gain media. The restriction of symmetry is due to light scattering caused by randomly oriented anisotropic crystals, whereas the solubility problem arises from the need for sufficient active dopants in the media. These criteria limit material choices and exclude materials that have superior thermo-mechanical properties than state-of-the-art laser materials. Alumina $\left(\mathrm{Al}_{2} \mathrm{O}_{3}\right)$ is an ideal example; it has a higher fracture strength and thermal conductivity than today's gain materials, which could lead to revolutionary laser performance. However, alumina has uniaxial optical proprieties, and the solubility of rare earths (REs) is two-to-three orders of magnitude lower than the dopant concentrations in typical RE-based gain media. We present new strategies to overcome these obstacles and demonstrate gain in a RE-doped alumina $\left(\mathrm{Nd}_{\mathrm{Al}} \mathrm{Al}_{2} \mathrm{O}_{3}\right)$ for the first time. The key insight relies on tailoring the crystallite size to other important length scales - the wavelength of light and interatomic dopant distances, which minimize optical losses and allow successful $\mathrm{Nd}$ doping. The result is a laser gain medium with a thermo-mechanical figure of merit of $R_{s} \sim 19,500 \mathrm{Wm}^{-1}$ a 24 -fold and 19,500-fold improvements over the high-energy-laser leaders Nd:YAG $\left(R_{\mathrm{s}} \sim 800 \mathrm{Wm}^{-1}\right)$ and $\mathrm{Nd}$ :Glass $\left(R_{\mathrm{s}} \sim 1 \mathrm{Wm}^{-1}\right)$, respectively. Moreover, the emission bandwidth of $\mathrm{Nd}: \mathrm{Al}_{2} \mathrm{O}_{3}$ is broad: $\sim 13 \mathrm{THz}$. The successful demonstration of gain and high bandwidth in a medium with superior $R_{\mathrm{s}}$ can lead to the development of lasers with previously unobtainable highpeak powers, short pulses, tunability, and high-duty cycles.
\end{abstract}

\section{Introduction}

The past decade has seen significant advances in the development of high-energy laser (HEL) technologies, with improvements in pumping technology, cavity design, cooling methods, and gain media quality. The search for gain media with superior optical, thermal, and mechanical properties remains intense because improvements in the material properties translate directly to increases in device

\footnotetext{
Correspondence: Javier E. Garay (jegaray@ucsd.edu)

'Advanced Materials Processing and Synthesis (AMPS) Laboratory, UC San Diego, La Jolla, CA 92093, USA

${ }^{2}$ Materials Science \& Engineering and Mechanical \& Aerospace Engineering, University of California, San Diego, La Jolla, CA 92093, USA
}

performance $^{1,2}$. Advanced laser gain materials that provide access to wavelength tunability, short pulses, and so on have paved the way for the study of light-matter interactions ${ }^{3-6}$, break-through medical applications ${ }^{7}$, and imaging/spectroscopy ${ }^{8}$.

Single crystals and glasses dominate the gain media market, but recent pioneering efforts have revealed advantages of polycrystalline ceramics such as improved mechanical properties and the possibility of gradient doping ${ }^{9}$. Ceramics also have the potential to alleviate one of the most pressing challenges in solid-state lasers-the thermal management of gain media. The power deliverable by a laser scales directly with thermal conductivity $k$,

\section{(c) The Author(s) 2018}

(c) (i) Open Access This article is licensed under a Creative Commons Attribution 4.0 International License, which permits use, sharing, adaptation, distribution and reproduction in any medium or format, as long as you give appropriate credit to the original author(s) and the source, provide a link to the Creative Commons license, and indicate if changes were made. The images or other third party material in this article are included in the article's Creative Commons license, unless indicated otherwise in a credit line to the material. If material is not included in the article's Creative Commons license and your intended use is not permitted by statutory regulation or exceeds the permitted use, you will need to obtain permission directly from the copyright holder. To view a copy of this license, visit http://creativecommons.org/licenses/by/4.0/. 
and the fracture stress $\sigma_{\mathrm{F}}$ places an ultimate limit of failure such that the figure of merit for a gain material is given by

$$
R_{\mathrm{s}}=\frac{k(1-v)}{\alpha E} \sigma_{\mathrm{F}}
$$

where $E$ is the elastic modulus, $\alpha$ is the coefficient of thermal expansion, and $v$ is Poisson's ratio. The low thermal conductivities of leading gain media $(\sim 1-2$ $\mathrm{Wm}^{-1} \mathrm{~K}^{-1}$ RE:Glass ${ }^{10}$ and $7-14 \mathrm{Wm}^{-1} \mathrm{~K}^{-1}$ RE:YAG ${ }^{11}$ ) continue to limit the power scaling of HELs.

Encouraged by pioneering work on cubic (optically isotropic) YAG ceramics that demonstrated lasing performance that rival their single-crystal counterparts ${ }^{12-14}$, researchers have been working on other cubic materials $^{15-18}$ as RE-host media because they have higher $k$ than YAG $^{18,19}$. Cubic-symmetry materials such as garnets and RE-sesquioxides are the mainstay of transparent ceramics because grain growth need not be avoided to mitigate birefringence scattering, and they readily accommodate RE dopants due to the similarity in ionic radii between dopant and cations ${ }^{20}$. The advances have been significant, but the improvements in thermo-mechanical characteristics have been insufficient to rival the state-of-the art gain media. To supplant RE:Glass and/or RE:YAG, a gain material with substantially better thermo-mechanical properties is needed.

For decades, researchers have worked on developing sapphire/alumina as a $\mathrm{RE}$ host because $\mathrm{Al}_{2} \mathrm{O}_{3}$ offers superior thermal conductivity $\left(k \sim 30-35 \mathrm{Wm}^{-1} \mathrm{~K}^{-1}\right)^{21}$ and a high-fracture toughness $\left(3.5 \mathrm{MPam}^{-1 / 2}\right)^{22}$, the combination of which leads to a superior thermal shock resistance $\left(R_{\mathrm{s}} \sim 19,500 \mathrm{Wm}^{-1}\right)$ compared to that of Glass $\left(R_{\mathrm{s}} \sim 1 \mathrm{Wm}^{-1}\right)^{23}$ and YAG $\left(R_{\mathrm{s}} \sim 800 \mathrm{Wm}^{-1}\right)^{1,24}$. Moreover, sapphire has a long history as a transition metal-doped gain media. Ruby $\left(\mathrm{Cr}: \mathrm{Al}_{2} \mathrm{O}_{3}\right)$ was the material used in the first laser ${ }^{25}$, and even today, titanium sapphire $\left(\mathrm{Ti}: \mathrm{Al}_{2} \mathrm{O}_{3}\right)$ is the most pervasive tunable laser medium ${ }^{26}$. The addition of RE dopants at levels sufficient for gain could allow for efficient emission at other wavelengths, resulting in a laser gain medium with a combination of thermal, mechanical, and optical properties that will lead to more powerful lasers for scientific, medical, industrial, and mobile applications.

Despite these promising attributes, producing laser grade $\mathrm{RE}: \mathrm{Al}_{2} \mathrm{O}_{3}$ ceramics is usually thought of as impossible. The two main obstacles are (1) the disparity in ionic radii between the $\mathrm{RE}^{3+}$ and $\mathrm{Al}^{3+}$, which leads to an equilibrium solubility of $\sim 10^{-3} \%{ }^{27}$, which is lower than necessary for gain, and (2) the optical anisotropy arising from the hexagonal crystal structure of $\mathrm{Al}_{2} \mathrm{O}_{3}$ leads to birefringence scattering that must be mitigated to achieve high transparency.

There have been significant efforts in developing pow$\operatorname{ders}^{28,29}$ and thin films ${ }^{30-34}$. Rand, Laine, and co-workers demonstrated the promising result of random lasing in strongly scattering rare-earth doped $\delta-\mathrm{Al}_{2} \mathrm{O}_{3}$ powders using direct electron-beam pumping ${ }^{28,} 29$. Significant progress has also been made in $\mathrm{Er}^{3+}$ and $\mathrm{Er}^{3+} / \mathrm{Yb}^{3+}$ doped alumina thin films fabricated by RF-magnetron sputtering $^{30}$ and pulsed laser deposition (PLD) ${ }^{31,} 32$ to concentrations as high as 1 at.\%, which resulted in amorphous and/or mixtures of amorphous and crystalline films with measurable photoluminescence (PL). Recently, Waeselmann et al. reported lasing in $\sim 2.6 \mu \mathrm{m}$ singlecrystal Nd:Sapphire thin films and reported dopant concentrations of $\sim 0.3-2$ at. $\%^{35-37}$. These reports are encouraging for producing lasers from $\mathrm{RE}: \mathrm{Al}_{2} \mathrm{O}_{3}$ media, but because of the low thermo-mechanical properties of powders and the difficulty in scaling thin films, they are not practical for HELs.

Translucent alumina ceramics have been produced for decades $^{38,39}$, but there are only a few reports on bulk ceramic $\mathrm{RE}: \mathrm{Al}_{2} \mathrm{O}_{3}$. Importantly, gain has not been demonstrated because $\mathrm{RE}: \mathrm{Al}_{2} \mathrm{O}_{3}$ ceramics have not reached the necessary optical quality ${ }^{19,} 40,41$. Krebs and Happek $^{40}$ used a laser-heated pedestal growth (LHPG) approach to produce single-crystal $\mathrm{Yb}^{3+}: \mathrm{Al}_{2} \mathrm{O}_{3}$ fibers, and Sanamyan ${ }^{41}$ et al. used a combination of powder synthesis and CAPAD to form dense $\mathrm{Er}^{3+}: \mathrm{Al}_{2} \mathrm{O}_{3}$. In both instances, single-site doping of RE onto the $\mathrm{Al}^{3+}$ lattice was possible at concentrations below the RE solubility limit, but at higher concentrations, secondary phases that hindered PL formed. It remains unclear whether these materials possess sufficient PL and low losses necessary for gain/lasing.

In our previous work ${ }^{19}$, we first reported PL in the visible with long lifetimes in transparent polycrystalline $\mathrm{Tb}^{3+}: \mathrm{Al}_{2} \mathrm{O}_{3}$. While promising for the feasibility of using $\mathrm{RE}: \mathrm{Al}_{2} \mathrm{O}_{3}$ ceramics as a gain media, we did not show evidence of stimulated emission or optical gain.

In this work, we present the first bulk polycrystalline $\mathrm{Nd}: \mathrm{Al}_{2} \mathrm{O}_{3}$ ceramics that exhibit stimulated emission and optical gain. Importantly, we demonstrate that gain can be achieved without single sight doping, i.e., with some $\mathrm{Nd}$ segregated to the grain boundaries. We report for the first time the presence of absorption bands in the transmission spectra, which confirm the presence of optically active $\mathrm{Nd}^{3+}$ present within the ceramic matrix. For the primary pumping band at $806 \mathrm{~nm}\left({ }^{4} \mathrm{I}_{9 / 2} \rightarrow{ }^{4} \mathrm{~F}_{5 / 2}\right)$, the absorption cross-section is $1.36 \times 10^{-20} \mathrm{~cm}^{2}$ and $1.69 \times 10^{-20} \mathrm{~cm}^{2}$ for 0.25 at.\% and 0.35 at.\% $\mathrm{Nd}: \mathrm{Al}_{2} \mathrm{O}_{3}$ ceramics, respectively.

In addition to the thermal management problem, $\mathrm{Nd}$ : $\mathrm{Al}_{2} \mathrm{O}_{3}$ addresses another long-standing problem in HEL technologies-producing broadband emission in REdoped media. Conventional gain media design aims for sharp single-site peaks that result in lower lasing thresholds. The advantage of high bandwidth is wavelength tunability and/or the generation of short pulses (increased peak energy). When pumping at $806 \mathrm{~nm}$ the ceramics 
show a $50 \mathrm{~nm}(\mathrm{FWHM}), 13 \mathrm{THz}$ peak at $1064 \mathrm{~nm},\left({ }^{4} \mathrm{~F}_{3 /}\right.$ $\left.{ }_{2} \rightarrow{ }^{4} \mathrm{I}_{11 / 2}\right)$. The fluorescence lifetime is $\sim 150 \mu \mathrm{s}$, which results in stimulated emission cross-sections as high as $\sim 9.8 \times 10^{-21} \mathrm{~cm}^{2}$. The $13 \mathrm{THz}$ gain bandwidth arising from multi-site doping of $\mathrm{Nd}$ in $\mathrm{Al}_{2} \mathrm{O}_{3}$ is a new record for $\mathrm{Nd}^{3+}$ gain media and could lead to pulses as short as $8 \mathrm{fs}$. Importantly, the measured gain coefficient, $g_{o}$, is as high as $2.42 \mathrm{~cm}^{-1}$ for 0.35 at. $\% \mathrm{Nd}^{3+}: \mathrm{Al}_{2} \mathrm{O}_{3}$ at $1064 \mathrm{~nm}$. The combination of thermal, mechanical, and optical properties offered by $\mathrm{Nd}^{3+}: \mathrm{Al}_{2} \mathrm{O}_{3}$ opens the door to producing HELs with superior performance. Moreover, the approach presented is applicable to other anisotropic material systems that are not readily considered for optical applications.

\section{Results}

Our strategy for obtaining gain in $\mathrm{Nd}_{2} \mathrm{Al}_{2} \mathrm{O}_{3}$ is a twofold design of nano/microstructure that relies on (1) crystallite sizes below the wavelength of pump and emitted light and (2) a dopant distribution in the grain volumes with minimal segregation at the grain boundaries. Figure 1 summarizes our strategy. In anisotropic ceramics with large grains, light is scattered at grain interfaces since they represent discontinuities in refractive index (Fig. 1a). However, as grain size decreases, the scattering efficiency of uniaxial grains is significantly lower ${ }^{38,39,42}$. Thus, finegrained ceramics can be highly transparent media with losses that are low enough to achieve optical gain (Fig. 1b).

In addition to low losses, RE-dopant concentrations must be within a critical range-high enough to achieve a sufficient absorption cross-section and emission crosssection, yet low enough to prevent concentration quenching (energy relaxation through phonon rather than radiative photon processes), which occurs when ions are too closely spaced.

Traditional material processing can be employed in systems such as glasses and garnets where RE solubility is high. However, in low solubility media, agglomeration occurs at grain boundaries (as shown in Fig. 1a). In the isotropic laser ceramics that have been demonstrated, grain sizes are typically $10-20 \mu \mathrm{m}^{14}$. In this large grain size case, there are relatively few grain boundary regions to accommodate the RE-dopant, and the average distance between RE ions decreases, resulting in luminescence quenching.

A key insight here is that the fine crystallite sizes that allow for high transparency in anisotropic polycrystalline materials can also play a crucial role in absorption/emission by providing a possibility for higher RE incorporation

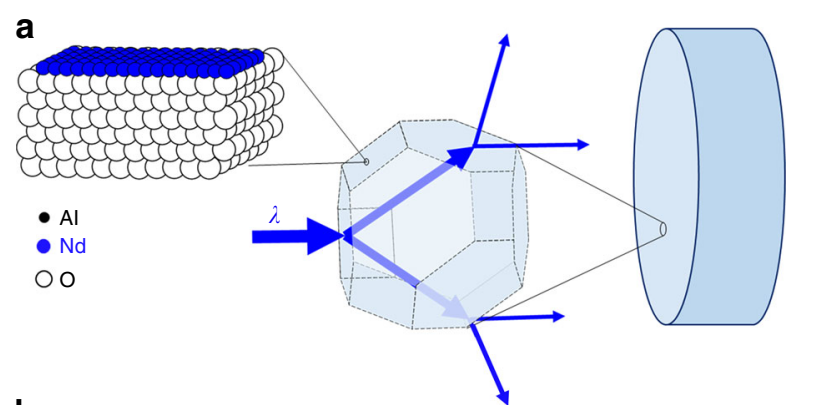

b

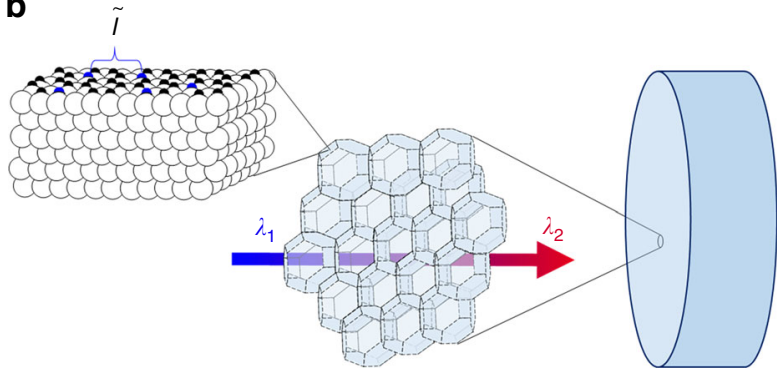

c

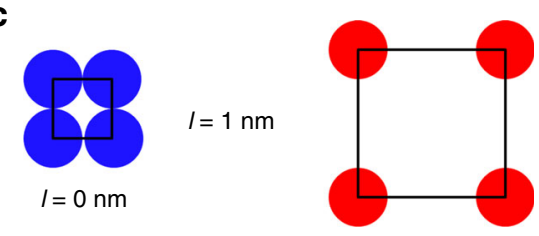

d

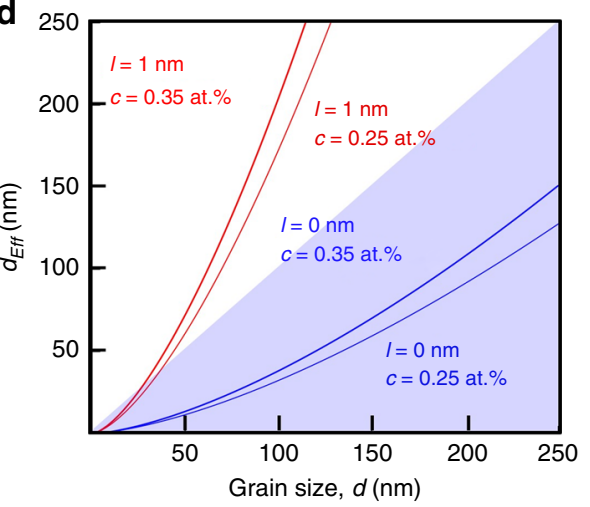

Fig. 1 Length scale relationships important for achieving gain in anisotropic ceramics. a Light is scattered at grain interfaces in ceramics with large crystallites because randomly oriented grains represent discontinuities in refractive index. RE segregation (represented as a close-packed monolayer) at the grain boundary on a section of $\mathrm{Al}_{2} \mathrm{O}_{3}$ (the blue atoms are $\mathrm{Nd}$, those in white are $\mathrm{O}$, and those in black are Al). $\mathbf{b}$ Scattering efficiency decreases significantly when pump $\left(\lambda_{1}\right)$ and emitted light $\left(\lambda_{2}\right)$ wavelengths are smaller than the grain size, permitting low optical losses. Small grains also permit spreading out of RE dopants at grain boundaries, increasing average interionic distance, $\tilde{l}$ allowing for optical gain. c A closepacked arrangement of dopant $I=0$ and one with realistic interionic distance for gain $(I=1 \mathrm{~nm})$. $\mathbf{d}$ Calculation of grain size necessary to accommodate all the dopants for a given dopant arrangement and concentration on the grain boundary, $d_{\text {eff }}$ vs. grain size using Eq. 4 for two concentrations and arrangements shown in (c) 
without luminescence quenching. By reducing grain size, grain boundary volume increases. When holding the global dopant concentration constant while decreasing grain size, RE dopants can 'spread out' along grain boundaries, increasing the average distance $\tilde{l}$ between REions (Fig. 1b). In other words, for very fine-grained materials, it should be possible to reach dopant concentrations sufficient to achieve gain even without solubility in the grain interior. The effective grain size $d_{\text {eff }}$ necessary to accommodate all the dopants on the grain boundaries rather than in the grain interiors depends on the arrangement of dopants on the boundary (function of $\tilde{l}$ ) and scales with $d^{3 / 2}$ (see the Materials and methods for details).

To illustrate this scenario, we plot $d_{\text {eff }}$ as a function of grain size (Eq. 4) in Fig. 1d for various concentrations (at.\% Nd) and dopant arrangements (Fig. 1c). The shaded regions in Fig. 1d are conditions in which it is possible to accommodate the global concentration of dopant atoms $c$ without any solubility in the grain. In the non-shaded regions, $d_{\text {eff }}>d$, meaning that it is not possible to accommodate all the dopant ions without solubility in the grains. In the limiting case example of a close-packed monolayer $(\tilde{l}=0)(\mathrm{Fig} .1 \mathrm{c})$, it is possible to accommodate $c=0.25$ at.\% and $c=0.35$ at.\% of $\mathrm{Nd}$ on the grain boundary of a grain with $d \sim 250 \mathrm{~nm}$. The close-packed monolayer case would likely not lead to gain because the distance between RE ions would result in luminescence quenching. Using a realistic value of $\tilde{l}=1 \mathrm{~nm}$, we see that grain sizes $<25 \mathrm{~nm}$ are necessary to accommodate 0.35 at.\% of Nd. The need for such small grain sizes is alleviated in our case because alumina does have solubility in the grain interiors which is likely higher near grain boundaries and can be increased under specific processing conditions as will be discussed below. It is interesting to discuss this level of dopant incorporation relative to $\mathrm{Nd}$ : YAG. The high Nd equilibrium solubility in YAG is due to the more open crystal structure leading to a lower cation density compared to that for alumina. Because the cation density is higher in $\mathrm{Al}_{2} \mathrm{O}_{3}$, the volume concentration, $c_{\mathrm{vol}}$, of $\mathrm{Nd}$ is significantly higher in $\mathrm{Al}_{2} \mathrm{O}_{3}$ vs. YAG for a given at.\% dopant. At $c=0.25$ at.\%, $c_{\mathrm{vol}}=1.18 \times 10^{20}$ atoms $/ \mathrm{cm}^{3}$ for $\mathrm{Nd}: \mathrm{Al}_{2} \mathrm{O}_{3}$, compared to $c_{\mathrm{vol}}=9.26 \times 10^{19}$ atoms $/ \mathrm{cm}^{3}$ for Nd:YAG, which is an increase of $\sim 26 \%$. Ultimately, this indicates that a 0.25 at.\% $\mathrm{Nd}: \mathrm{Al}_{2} \mathrm{O}_{3}$ ceramic will contain a suitable concentration of $\mathrm{RE}$ for lasing.

To obtain gain in an $\mathrm{Nd}: \mathrm{Al}_{2} \mathrm{O}_{3}$ bulk polycrystalline material, processing techniques that will produce fully dense ceramics with fine average grain size (AGS) and/or that offer processing "windows" with increased rare-earth solubility are needed. Fortunately, the Nd solubility can be increased using high heating and cooling rates (to be discussed below), easing the necessity for extremely fine grains. Using a solid-state powder processing route along with a one-step simultaneous reaction/densification approach with CAPAD, we can achieve an $\mathrm{Nd}$ concentration as high as 0.35 at.\% ( $\mathrm{Nd}: \mathrm{Al}$ ratio).

At processing temperatures of $1200{ }^{\circ} \mathrm{C}$ (un-doped) and $1260^{\circ} \mathrm{C}$ (Nd-doped), the samples have a fine AGS of $\sim 250 \mathrm{~nm}$, near the theoretical density, and are phase pure. As such, they possess long-range transparency (Fig. 2a) and when doped emit light at the characteristic $\mathrm{Nd}^{3+}$ wavelength of $1064 \mathrm{~nm}$ when pumped with $806 \mathrm{~nm}$, which are prerequisites for gain. However, all samples processed at $1300^{\circ} \mathrm{C}$ are diffuse and white due to an increased AGS to $\sim 2.1 \mu \mathrm{m} \pm 0.25 \mu \mathrm{m}$ for the un-doped $\alpha$ $\mathrm{Al}_{2} \mathrm{O}_{3}$ and $1.9 \mu \mathrm{m} \pm 0.22 \mu \mathrm{m}$ and $1.87 \mu \mathrm{m} \pm 0.23 \mu \mathrm{m}$ for 0.25 at.\% and 0.35 at.\% $\mathrm{Nd}: \mathrm{Al}_{2} \mathrm{O}_{3}$, respectively. At these larger grain sizes, the scattering efficiency is significantly higher (Fig. 1a).

The CAPAD processing parameters were varied to optimize the microstructure and properties of various concentrations of $\mathrm{Nd}: \mathrm{Al}_{2} \mathrm{O}_{3}$ (see the Materials and methods for details). Figure 2a shows the effect of CAPAD temperature on the relative density of un-doped samples and others doped with 0.25 and 0.35 at.\% Nd. The results show a sigmoidal temperature dependence, where the density increases abruptly at a temperature referred to as the densification on-set temperature, $T_{\mathrm{OD}}$. There is a clear influence of $\mathrm{Nd}$ dopant on $T_{\mathrm{OD}}$. For the $\mathrm{Nd}$-doped $\mathrm{Al}_{2} \mathrm{O}_{3}$ samples, $T_{\mathrm{OD}}$ is $\sim 200^{\circ} \mathrm{C}$ higher than in the un-doped case (a shift from $\sim 900^{\circ} \mathrm{C}$ to $\sim 1100^{\circ} \mathrm{C}$ ). There is also a small effect between the two different $\mathrm{Nd}$ concentrations on $T_{\mathrm{OD}}$. The densities of the 0.25 at.\% Nd samples are slightly higher than those for the 0.35 at.\% Nd samples at most processing temperatures. $\mathrm{Nd}$ addition also affects the temperature required to obtain full density; relative densities $>99 \%$ are achieved in the un-doped $\mathrm{Al}_{2} \mathrm{O}_{3}$ case at $1200{ }^{\circ} \mathrm{C}$ and $\sim 1260^{\circ} \mathrm{C}$ for the $\mathrm{Nd}: \mathrm{Al}_{2} \mathrm{O}_{3}$ samples.

We have previously observed reduced densification kinetics caused by RE addition in reaction/densification of ceramics $^{19,43}$. This is due primarily to the presence of the $\mathrm{RE}$ oxide dopant powder along the particle/grain boundaries when the two phases are still separate reactants. In our previous work on alumina with $\mathrm{Tb}$ as a dopant, the decrease in density was lower compared to the present case of $\mathrm{Nd}$ at similar global concentrations ${ }^{19}$. The difference in behavior between the $\mathrm{Nd}$ and $\mathrm{Tb}$ dopants can be attributed to the larger ionic radius of $\mathrm{Nd}^{3+}(0.983 \AA)$ compared to $\mathrm{Tb}^{3+}(0.923 \AA)$. A similar shift in the $T_{\mathrm{OD}}$ with respect to $\mathrm{RE}$ ionic radius was reported for a $\mathrm{Nd}^{3+}$, $\mathrm{Eu}^{3+}$, and $\mathrm{Er}^{3+}$ doped $\mathrm{Al}_{2} \mathrm{O}_{3}$ system (0.2 at.\% RE to $\mathrm{Al}_{2} \mathrm{O}_{3}$ ratio, $\sim 0.04$ at.\% RE:Al) via free-sintering and hot-pressing by Drdlík et al. ${ }^{44}$. It is worth noting that in their work, the $T_{\mathrm{OD}}$ was significantly higher $\left(>1400^{\circ} \mathrm{C}\right)$, and a lower $\sim 98 \%$ relative density was achieved at processing temperatures $>1500^{\circ} \mathrm{C}$. The higher processing temperatures resulted in larger AGS $(>500 \mathrm{~nm})$ which diminished the material transmission and dopant concentration. 


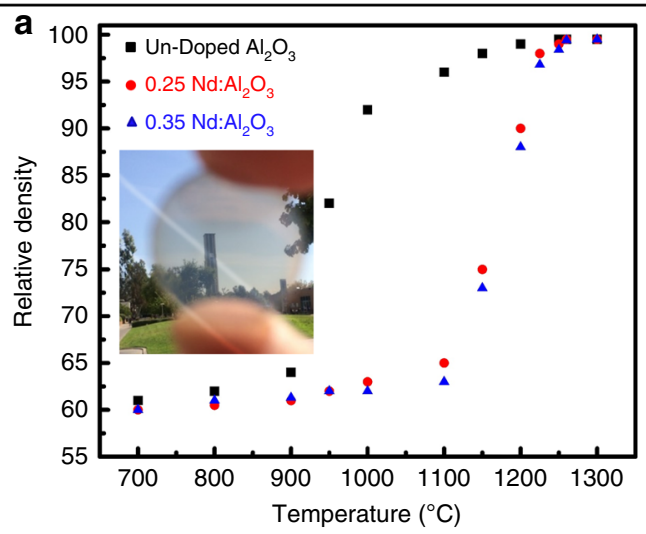

b

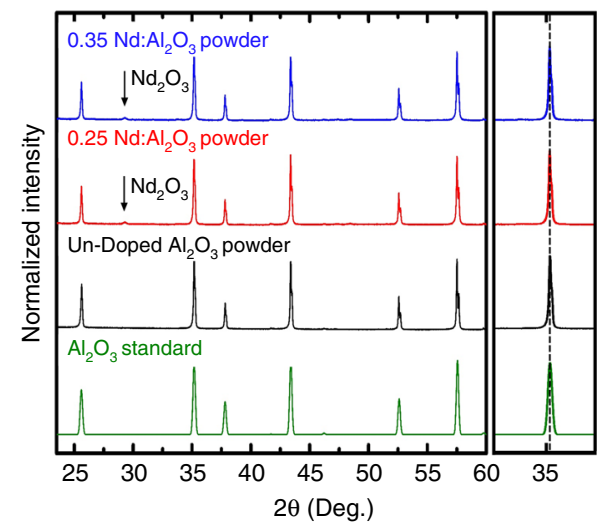

C

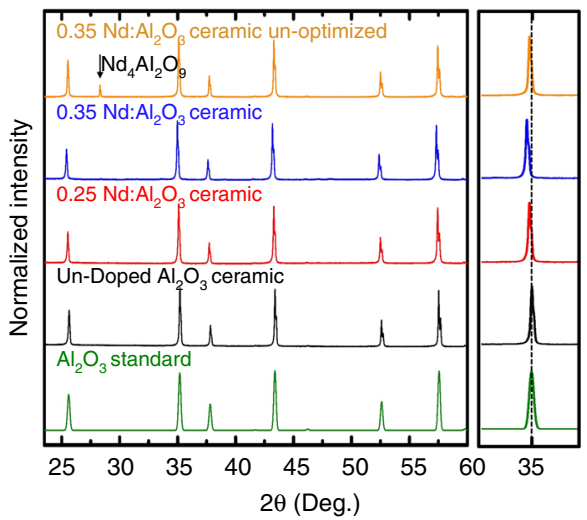

Fig. 2 Physical and microstructural characterization of $\mathrm{Nd}_{2} \mathrm{Al}_{2} \mathrm{O}_{3}$. a the effect of CAPAD temperature on the relative density of un-doped and samples doped with 0.25 and 0.35 at.\% Nd. The inset is a picture demonstrating long range transparency. $\mathbf{b}$ XRD profiles of the starting $\mathrm{Al}_{2} \mathrm{O}_{3}$ and $\mathrm{Nd}$-doped $\mathrm{Al}_{2} \mathrm{O}_{3}$ powders. For the 0.25 and $0.35 \mathrm{at}$. \% powders, there are peaks attributed to the $\mathrm{Nd}_{2} \mathrm{O}_{3}$ dopant as indicated by arrows. c XRD profiles of $\mathrm{Al}_{2} \mathrm{O}_{3}$ and Nd-doped ceramics. The un-

optimized Nd-doped sample shows a clear secondary phase (indicated with an arrow). The optimized samples do not show signs of a secondary phase present. The inset on the right clearly shows a peak shift relative to an $a-\mathrm{Al}_{2} \mathrm{O}_{3}$ standard (dashed line) for optimized $\mathrm{Nd}: \mathrm{Al}_{2} \mathrm{O}_{3}$

Figure $2 \mathrm{~b}$ shows $\mathrm{X}$-ray diffraction (XRD) profiles of the $\mathrm{Al}_{2} \mathrm{O}_{3}$ and $\mathrm{Al}_{2} \mathrm{O}_{3}+\mathrm{Nd}_{2} \mathrm{O}_{3}$ powders after planetary ball milling (PBM) with varying $\mathrm{Nd}$ concentrations. These
XRD spectra reveal a peak at $2 \theta=30.72^{\circ}$, corresponding to the highest intensity peak for $\mathrm{Nd}_{2} \mathrm{O}_{3}$. Comparison of the XRD of the PBM starting powders to the $\alpha-\mathrm{Al}_{2} \mathrm{O}_{3}$ reference does not show discernible peak shifts irrespective of $\mathrm{Nd}$ concentration, suggesting that $\mathrm{Nd}^{3+}$ doping into the $\alpha-\mathrm{Al}_{2} \mathrm{O}_{3}$ matrix did not occur through mechanical alloying during PBM. This is expected considering the relatively low energy of the PBM conditions.

Figure 2c shows XRD spectra of fully dense polycrystals using optimized and non-optimized CAPAD conditions. The heating rates, processing temperatures, and hold times of the optimized and non-optimized cases were similar $\left(\mathrm{HR}=300^{\circ} \mathrm{C} \mathrm{min}^{-1}, T=1260^{\circ} \mathrm{C}\right.$, and $\mathrm{HT}=5$ $\mathrm{min}$ ); the largest difference in each case was in the cooling rate, $\mathrm{CR}$, which was significantly higher for the optimized case (Optimized $\mathrm{CR}=300^{\circ} \mathrm{C} \mathrm{min}^{-1}$ and Non-optimized $\mathrm{CR} \sim 42^{\circ} \mathrm{C} \mathrm{min}^{-1}$ ). The XRD spectra of the non-optimized sample reveal an unwanted secondary phase, $\mathrm{Nd}_{4} \mathrm{Al}_{2} \mathrm{O}_{9}$, (marked with an arrow). The highest intensity alumina peak is also at the same angle compared to the un-doped alumina ceramic, suggesting that $\mathrm{Nd}$ had not been adequately incorporated in the lattice.

By contrast, XRD of the ceramics processed using optimized CAPAD conditions reveal single phase $\alpha-\mathrm{Al}_{2} \mathrm{O}_{3}$ with no signal from the starting $\mathrm{Nd}_{2} \mathrm{O}_{3}$ or from the ternary $\mathrm{Nd}_{4} \mathrm{Al}_{2} \mathrm{O}_{9}$ and $\mathrm{NdAlO}_{3}$ phases. This is in contrast to some previous reports that showed secondary phases in $\mathrm{RE}$-doped $\alpha-\mathrm{Al}_{2} \mathrm{O}_{3}$ that have been produced at RE concentrations above the equilibrium solubility limit with other processing approaches ${ }^{45,}{ }^{46}$. Moreover, the XRD spectra of the optimized Nd-doped samples reveal clear peak shifts to lower angles with increasing $\mathrm{Nd}$ concentration. The dashed line in the inset on the right is the location of highest intensity peak from the reference. This shift is evidence of stretching of the $\alpha-\mathrm{Al}_{2} \mathrm{O}_{3}$ lattice from the doping of $\mathrm{Nd}$ ions caused by CAPAD processing. The absence of the $\mathrm{Nd}_{2} \mathrm{O}_{3}$ reactant and ternary phases strongly indicates a fundamental difference in the reaction kinetics associated with CAPAD processing in comparison to that for traditional processing approaches.

We attribute the ability to incorporate high concentrations of $\mathrm{RE}$ into $\mathrm{Al}_{2} \mathrm{O}_{3}$ to the high heating and cooling rates we employed in CAPAD. The high heating rate $\sim 300^{\circ} \mathrm{C} \mathrm{min}{ }^{-1}$ allows us to reach the desired temperature quickly, minimizing unwanted grain growth ${ }^{19,} 47$ while achieving a near theoretical relative density, which are prerequisites for high optical transparency in $\mathrm{Al}_{2} \mathrm{O}_{3}$. We previously observed an increase in reaction kinetics associated with high heating rates in the Ce:YAG system ${ }^{43}$. We found $\sim 20$-fold increases in reaction coefficients in comparison to reaction/densification in free-sintering using much slower heating rates. Since the largest difference between the optimized and un-optimized samples in this 
work was in the CR, we believe this parameter also plays a crucial role in $\mathrm{RE}$ incorporation. The $\mathrm{Nd}$ solubility increases at higher temperatures so that the high CR has the effect of "freezing in" $\mathrm{Nd}$, thus minimizing segregation. There is a synergistic effect between fine AGS and RE incorporation during CAPAD. A more detailed investigation of the relationships between $\mathrm{CR}$, microstructure, and optical properties is underway but is beyond the scope of this communication.

We used TEM to further confirm incorporation of $\mathrm{Nd}$ into the alumina matrix. A high-angle annular dark-field (HAADF) TEM micrograph and corresponding energydispersive $\mathrm{X}$-ray spectroscopy (EDS) distribution maps of a 0.35 at.\% Nd: $\mathrm{Al}_{2} \mathrm{O}_{3}$ polycrystal $\left(T=1260^{\circ} \mathrm{C}, \mathrm{HT}=5\right.$ min, $\quad \mathrm{HR}=300^{\circ} \mathrm{Cmin}^{-1}$, and $\mathrm{CR}=300^{\circ} \mathrm{Cmin}^{-1}$ ) are shown in Fig. 3a. The EDS maps reveal that a significant portion of the Nd dopant is found within the matrix and along some grain boundaries and triple points. The minimal segregation corroborates the XRD spectra in Fig. 2c, which shows a shift in the XRD peaks to lower $2 \theta$ angles and does not show the presence of unwanted secondary phases. This is in-line with observations by Rohrer, Harmer and co-workers ${ }^{48,} 49$ showing differences in the local grain boundary structure in RE-doped $\alpha$ $\mathrm{Al}_{2} \mathrm{O}_{3}$ and an increasing concentration gradient from the grain interior towards the grain boundary.
The optical transparencies of the consolidated bulk Nd: $\mathrm{Al}_{2} \mathrm{O}_{3}$ polycrystals are shown in Fig. 4a with the corresponding transmission spectra presented in Fig. 4b. The transmission values of our undoped alumina ceramics rival those previously reported for sinter-HIPed samples ${ }^{38}$ and high pressure CAPAD ${ }^{50}$. More importantly, the $\mathrm{Nd}$-doped samples have similar transmissions. In the area of interest for lasing of $\mathrm{Nd}^{3+}$ media at $\sim 1064 \mathrm{~nm}$ $\left({ }^{4} \mathrm{~F}_{3 / 2} \rightarrow{ }^{4} \mathrm{I}_{11 / 2}\right.$ transition), the transmission is $\sim 75 \%$ for the $\mathrm{Nd}: \mathrm{Al}_{2} \mathrm{O}_{3}$. We attribute this high transmission to the high density (>99\%), fine AGS ( 250 nm), low Nd segregation, and lack of secondary (undesired) phases in the $\mathrm{Nd}: \mathrm{Al}_{2} \mathrm{O}_{3}$. It is important to note that this transmission is not corrected for refection losses. When corrected for reflection losses, the transmission at $1064 \mathrm{~nm}$ is $\sim 90 \%$, leading to a loss coefficient (absorption+scattering) of $\sim 1.317 \mathrm{~cm}^{-1}$. For laser oscillation, a gain greater to this total loss is required for net positive gain. Our single-pass gain measurements presented below show that the optical quality of our ceramics is indeed suitable for lasing.

\section{Discussion}

One remarkable difference in the $\mathrm{Nd}: \mathrm{Al}_{2} \mathrm{O}_{3}$ transmission spectra is the presence of the absorption bands centered at $\lambda=583 \mathrm{~nm}(2.12 \mathrm{eV}), 745 \mathrm{~nm}(1.85 \mathrm{eV})$, and $806 \mathrm{~nm}(1.54 \mathrm{eV})$, which correspond to the ${ }^{4} \mathrm{G}_{5 / 2},{ }^{4} \mathrm{~F}_{7 / 2}$,

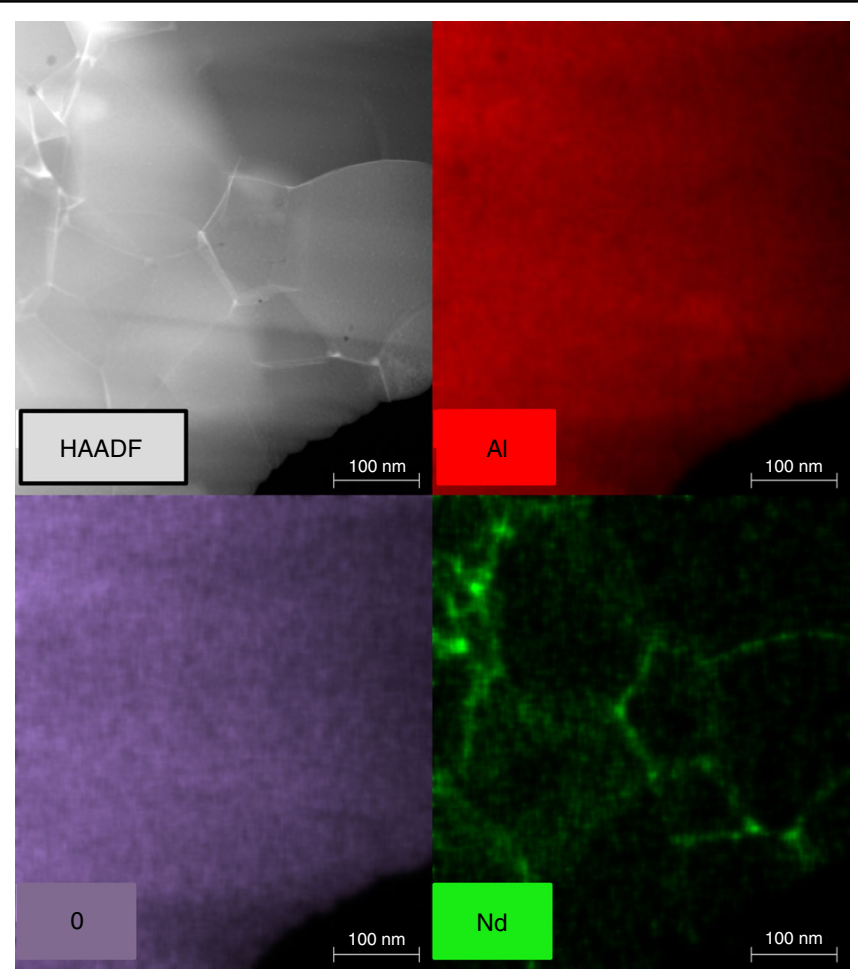

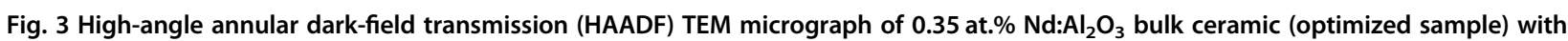
corresponding energy-dispersive $\mathrm{X}$-ray spectroscopy (EDS) elemental maps for Al, $\mathbf{O}$, and Nd (L-Lines). The EDS maps reveal that a significant portion of the $\mathrm{Nd}$ dopant is found within the matrix. In addition, there is some $\mathrm{Nd}$ along some grain boundaries and triple points 
a

$0.35 \mathrm{Nd}: \mathrm{Al}_{2} \mathrm{O}_{3}$

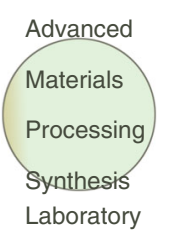

$0.25 \mathrm{Nd}: \mathrm{Al}_{2} \mathrm{O}_{3}$

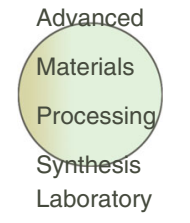

Un-doped $\mathrm{Al}_{2} \mathrm{O}_{3}$

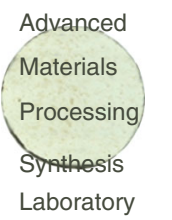

b 100

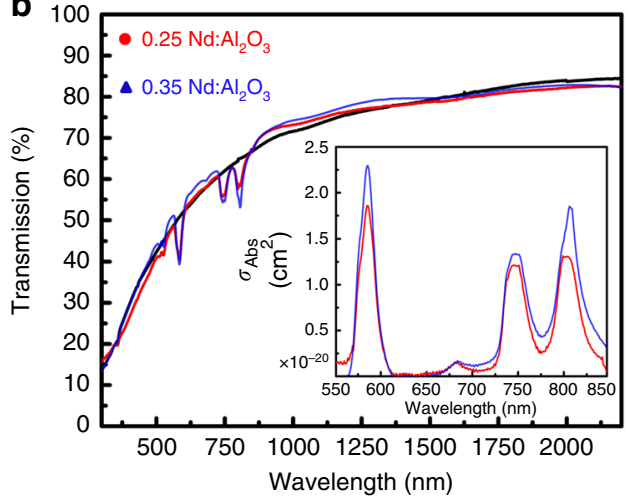

C

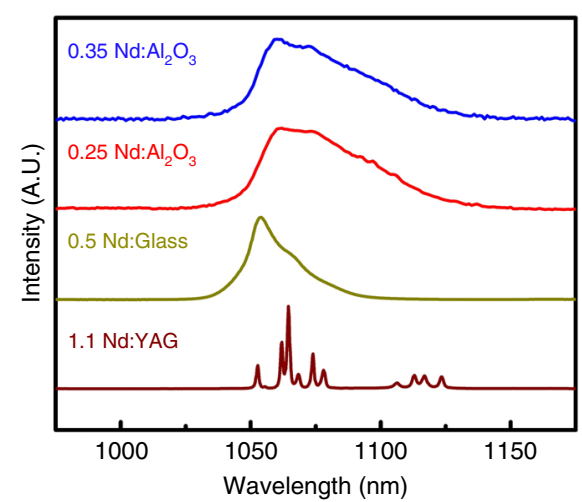

d

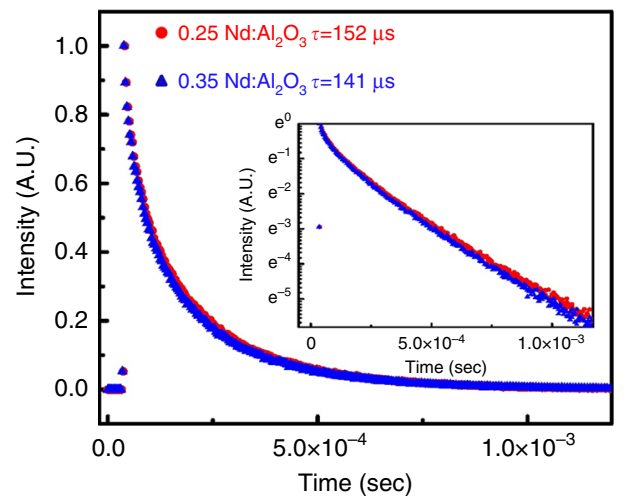

e

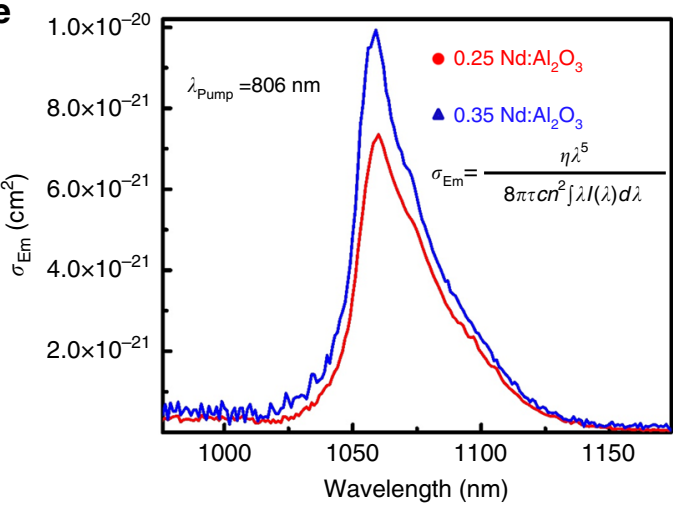

Fig. 4 Optical properties of $\mathbf{N d}: \mathrm{Al}_{2} \mathrm{O}_{3}$. a Pictures of $\mathrm{Nd}$-doped and undoped ceramics. $\mathbf{b}$ Transmission measurements of the $\mathrm{Nd}$ : $\mathrm{Al}_{2} \mathrm{O}_{3}$ and undoped $\mathrm{Al}_{2} \mathrm{O}_{3}$. All the ceramics show high transmission, and importantly, the Nd-doped samples have absorption bands characteristic of $\mathrm{Nd}^{3+}$ transmission. The corresponding absorption cross sections in the area of interest are shown in the inset. c PL emission spectra for the 0.25 at.\% and 0.35 at.\% Nd ${ }^{3+}$ : $\mathrm{Al}_{2} \mathrm{O}_{3}$ samples along with 0.5 at.\% Nd $\mathrm{Nd}^{3+}$ :Glass and 1.1 at.\% $\mathrm{Nd}^{3+}: \mathrm{YAG}$ single crystal. The pump source is an $806 \mathrm{~nm}$ laser diode. The PL reveal broadened lines attributed to the ${ }^{4} \mathrm{~F}_{3 / 2} \rightarrow{ }^{4} \mathrm{I}_{11 / 2}$ electronic transitions. $\mathbf{d}$ the radiative lifetimes at $1064 \mathrm{~nm}$ for the $\mathrm{Nd}_{\mathrm{A}} \mathrm{Al}_{2} \mathrm{O}_{3}$ ceramics produced under similar CAPAD processing conditions, and log scale intensity is also shown. The lifetimes are $152 \mu \mathrm{s}$ and $141 \mu \mathrm{s}$ for the 0.25 and 0.35 at.\% $\mathrm{Nd}^{\mathrm{A}} \mathrm{Al}_{2} \mathrm{O}_{3}$, respectively. e the resultant emission cross-sections, $\sigma_{E m}$, using the Fuchtbauer-Landenburg relationship (Eq. 2). The emission cross section peak is $\sigma_{\mathrm{Em}}=7.5 \times 10^{-21} \mathrm{~cm}^{2}$ for 0.25 at. $\%$ and $9.8 \times 10^{-21} \mathrm{~cm}^{2}$ for 0.35 at. $\% \mathrm{Nd}^{\mathrm{Al}} \mathrm{Al}_{2} \mathrm{O}_{3}$ ceramics

and ${ }^{4} \mathrm{~F}_{5 / 2}$ Stark transitions from the ${ }^{4} \mathrm{I}_{9 / 2}$ manifold ${ }^{51,52}$. We believe this is the first time that absorption bands associated with $\mathrm{RE}$ doping have been observed in $\mathrm{Al}_{2} \mathrm{O}_{3}$ transmission spectra and strongly evidence that the $\mathrm{Nd}^{3+}$ dopant is optically active within the ceramic matrix ${ }^{53}$. The center of the $\mathrm{Nd}^{3+}$ absorption bands in $\mathrm{Al}_{2} \mathrm{O}_{3}$ are slightly blue shifted $(\sim 2.5 \mathrm{~nm})$ in comparison with that for Nd:YAG single crystals ${ }^{51,52}$. The absorption bands are broadened in $\mathrm{Nd}: \mathrm{Al}_{2} \mathrm{O}_{3}$ to $\Delta \lambda \sim 23 \mathrm{~nm}$ (FWHM) from $\sim \Delta \lambda \sim 2 \mathrm{~nm}$ compared to Nd:YAG ${ }^{53}$, which is consistent with our observations that the $\mathrm{Nd}^{3+}$ is found on multiple doping sites within the alumina matrix. Moreover, the depth of the absorption bands increases with dopant concentration, indicating greater optical activity from the $\mathrm{Nd}^{3+}$ ions within the 0.35 at.\% $\mathrm{Nd}: \mathrm{Al}_{2} \mathrm{O}_{3}$ sample.

The absorption cross-sections $\sigma_{\mathrm{abs}}$ for the region of interest are shown in the inset in Fig. 4b. These $\sigma_{\text {abs }}$ were calculated from the measured transmissions corrected for reflection and scattering losses ${ }^{39}$. In dense polycrystalline ceramics with anisotropic crystal structure (uniaxial in this case), one should correct for scattering losses caused by the birefringence to not overestimate $\sigma_{\mathrm{abs}}$. We corrected for scattering losses using the Rayleigh-Gans-Debye (RGD) approach in which the scattering has a $1 / \lambda^{2}$ dependence, as discussed previously for transition metaldoped alumina ${ }^{39}$. The excellent agreement between the calculated and measured transmission spectra (not shown here) for the un-doped $\mathrm{Al}_{2} \mathrm{O}_{3}$ ceramics confirm that the uniaxial crystal structure is the main source of scattering as opposed to porosity and validates the use of the correction method.

For the ${ }^{4} \mathrm{~F}_{5 / 2}$ transition, which is of interest for diodepumped lasers, the peak $\sigma_{\mathrm{abs}}$ are $1.36 \times 10^{-20} \mathrm{~cm}^{2}$ and $1.69 \times 10^{-20} \mathrm{~cm}^{2}$ for the 0.25 at.\% and 0.35 at. $\% \mathrm{Nd}: \mathrm{Al}_{2} \mathrm{O}_{3}$, respectively. These cross-sections compare well with single-crystal 1.1 at.\% Nd:YAG, $\left(\sigma_{\text {abs }} \sim 7.7 \times 10^{-20} \mathrm{~cm}^{2}\right)$. The slightly lower $\sigma_{\mathrm{abs}}$ in $\mathrm{Nd}: \mathrm{Al}_{2} \mathrm{O}_{3}$ may be caused by $\mathrm{Nd}$ sites that are not optically active or absorption band 
broadening, which also occurs in Nd:Glass and $\mathrm{Nd}$ : $\mathrm{YVO}_{4}{ }^{54,55}$.

Figure 4c presents the PL emission spectra for the 0.25 at.\% and 0.35 at.\% $\mathrm{Nd}^{3+}: \mathrm{Al}_{2} \mathrm{O}_{3}$ ceramics, 0.5 at.\% $\mathrm{Nd}^{3+}$ : Glass (Schott), and 1.1 at.\% $\mathrm{Nd}^{3+}$ :YAG (single crystal, Litton Technologies, Inc.) resulting from pumping at $\lambda=$ $806 \mathrm{~nm}$. All the media show emission at similar wavelengths but different line shapes and bandwidths for the ${ }^{4} \mathrm{~F}_{3 / 2} \rightarrow{ }^{4} \mathrm{I}_{11 / 2}$ transition. The single-crystal profile shows narrow, well-defined peaks typical of single site doping. By contrast, emission peaks in $\mathrm{Nd}^{3+}: \mathrm{Al}_{2} \mathrm{O}_{3}$ appear to be inhomogeneously broadened, similar to that for $\mathrm{Nd}^{3+}$ : Glass, although the overall PL bandwidth is wider than for the laser glass. Inhomogeneous broadening of the $\mathrm{Nd}^{3+}$ : $\mathrm{Al}_{2} \mathrm{O}_{3}$ emission lines is not surprising given that $\mathrm{Nd}$ ions are found on multiple sites, including at grain interiors, grain boundaries and triple points (Fig. 3). This broadening contrasts with PL behavior reported by Waeselmann in 2 at.\% $\mathrm{Nd}: \mathrm{Al}_{2} \mathrm{O}_{3}$ on thin films produced with PLD. These authors demonstrated lasing in epitaxial films that showed narrow emission lines for the ${ }^{4} \mathrm{~F}_{3 / 2} \rightarrow{ }^{4} \mathrm{I}_{11 / 2}$ transition, producing PL at $1097 \mathrm{~nm}^{35}$. The shifted emission peak compared to our results and single-crystal Nd:YAG is not surprising because epitaxial thin films often display shifts compared to bulk materials. The authors attribute the sharp emission peaks to single site doping, in particular the substitution of $\mathrm{Nd}^{3+}$ onto the $\mathrm{Al}^{3+}$ lattice. Despite the sharp PL peaks, they did not observe a significant absorption cross-section, which they attribute to the possibility of dead Nd sites, which do not contribute to absorption or PL.

The gain bandwidth $\left(G_{\mathrm{bw}}\right)$ can be approximated by measuring the full-width at half-maximum (FWHM) of the PL emission peaks. We obtain $G_{\mathrm{bw}}=0.6 \mathrm{~nm}(0.16$ $\mathrm{THz}$ ) for $\mathrm{Nd}^{3+}$ :YAG and $G_{\mathrm{bw}}=20 \mathrm{~nm}(5.4 \mathrm{THz})$ for $\mathrm{Nd}^{3+}$ :Glass, which agree well with previous measurements ${ }^{53,55}$. Remarkably, the $G_{\mathrm{bw}}$ are $\sim 49 \mathrm{~nm}(13 \mathrm{THz})$ which we believe are the highest bandwidths measured for $\mathrm{Nd}^{3+}$ in any media. For bandwidth-limited pulses, the achievable pulse duration of a gain medium is determined by $G_{\mathrm{bw}}$. The broader the emission bandwidth, the shorter the pulse; the pulse width can be estimated using $\Delta \tau_{\mathrm{P}}=1 /$ $G_{\mathrm{bw}}$. Using $G_{\mathrm{bw}}$ measurements, we find $\Delta \tau_{\mathrm{P}} \sim 7.7$ fs. The large bandwidth of $\mathrm{Nd}^{3+}: \mathrm{Al}_{2} \mathrm{O}_{3}$ promises the generation of high peak-power lasers by generating ultra-short time pulses. These bandwidth-limited pulse widths represent a 2.5 -fold increase in the single-shot peak power over $\mathrm{Nd}^{3+}$ : Glass and $>80$-fold increase over $\mathrm{Nd}^{3+}$ :YAG $\left(\Delta \tau_{\mathrm{P}}=6.3 \mathrm{ps}\right.$ for $\mathrm{Nd}^{3+}$ :YAG and $\Delta \tau_{\mathrm{P}}=18.5$ fs for $\mathrm{Nd}^{3+}$ :Glass) through pulse width compression. These estimated improvements are conservative because thermal shock resistance for $\mathrm{Nd}$ : $\mathrm{Al}_{2} \mathrm{O}_{3}\left(R_{\mathrm{s}} \sim 19,500 \mathrm{Wm}^{-1}\right)$ is superior to Nd:YAG $\left(R_{\mathrm{s}} \sim 800\right.$ $\left.\mathrm{Wm}^{-1}\right)$ and Nd:Glass $\left(R_{\mathrm{s}} \sim 1 \mathrm{Wm}^{-1}\right)$, indicating the possibility of scaling peak-power extraction accordingly.
Given these interesting absorption and PL characteristics, we measured the radiative lifetimes, $\tau$, at $1064 \mathrm{~nm}$ for the $\mathrm{Nd}: \mathrm{Al}_{2} \mathrm{O}_{3}$ ceramics. The lifetimes are $152 \mu \mathrm{s}$ and $141 \mu$ s for the 0.25 and 0.35 at.\% $\mathrm{Nd}_{2} \mathrm{Al}_{2} \mathrm{O}_{3}$, respectively (Fig. 4d). These lifetimes compare well with those of other proven gain media; they are longer than those observed by Waeselmann in 2 at.\% Nd:Sapphire but are shorter than those of Nd:YAG $\left(230 \mu \mathrm{s}^{54}\right)$ and Nd:Glass $\left(330 \mu \mathrm{s}^{24}\right)$. The small decrease in $\tau$ as the $\mathrm{Nd}$ concentration increases for the 0.25 to the 0.35 at.\% samples may indicate the onset of concentration quenching. By contrast, the un-optimized 0.35 at.\% $\mathrm{Nd}: \mathrm{Al}_{2} \mathrm{O}_{3}$ sample results in a significant decrease in $\tau \sim 50 \mu \mathrm{s}$. This is not surprising because we observed clear secondary phases in the XRD analysis. Further spectroscopic and processing studies are required to fully understand concentration quenching in $\mathrm{Nd}: \mathrm{Al}_{2} \mathrm{O}_{3}$.

From the PL emission spectra, we determined the emission cross-sections $\sigma_{\mathrm{Em}}$ using the Fuchtbauer-Landenburg relationship $^{56}$,

$$
\sigma_{\mathrm{Em}}=\frac{n \lambda^{5}}{8 \pi \tau c n^{2} \int I(\lambda) \mathrm{d} \lambda}
$$

The $\sigma_{\mathrm{Em}}$ are large and adequate for lasing across the PL bandwidth; the peak $\sigma_{\mathrm{Em}}=7.5 \times 10^{-21} \mathrm{~cm}^{2}$ for $0.25 \mathrm{at} \%$ and $9.8 \times 10^{-21} \mathrm{~cm}^{2}$ for 0.35 at.\% optimized ceramics. These $\sigma_{\mathrm{Em}}$ are consistent with $\sigma_{\mathrm{Abs}}$ derived from the measured transmission spectra. By contrast, $\sigma_{\mathrm{Em}}$ is $3.1 \times$ $10^{-22} \mathrm{~cm}^{2}$ for the un-optimized sample. The substantially lower $\sigma_{\mathrm{Em}}$ proves that the presence of second phases deteriorates the optical activity for the Nd-dopant.

To unambiguously ascertain the viability for lasing in $\mathrm{Nd}^{3+}: \mathrm{Al}_{2} \mathrm{O}_{3}$, we measured their small-signal gain coefficients using a single pass arrangement similar to one used by $\mathrm{Lai}^{57}$. The schematic for the optical arrangement is shown in Fig. 5a. Briefly, a $1064 \mathrm{~nm}$ probe beam was passed through a specimen at a constant incident power. An $806 \mathrm{~nm}$ pump laser was introduced onto the same spatial location on the test specimens using a dichroic optic with high-transmission (99\% at $806 \mathrm{~nm}$ ) and highreflection $(99.5 \%$ at $1064 \mathrm{~nm})$. The increase/decrease in the probe beam intensity as a function of absorbed pump power was monitored by the same photodiode. We used a modified version of the Beer-Lambert law for homogenous/Doppler broadened gain media to measure gain coefficients:

$$
I_{\mathrm{F}}(z)=I_{\mathrm{o}}(z) e^{\left[g_{0}\right] \cdot z}
$$

where $I_{\mathrm{o}}(z)$ and $I_{\mathrm{F}}(z)$ are the intensities of the probe laser after having passed through the test specimen of thickness $z$, prior to and with pumping, respectively, and $g_{0}$ is the small-signal gain coefficient, obtained here in a singlepass arrangement. 


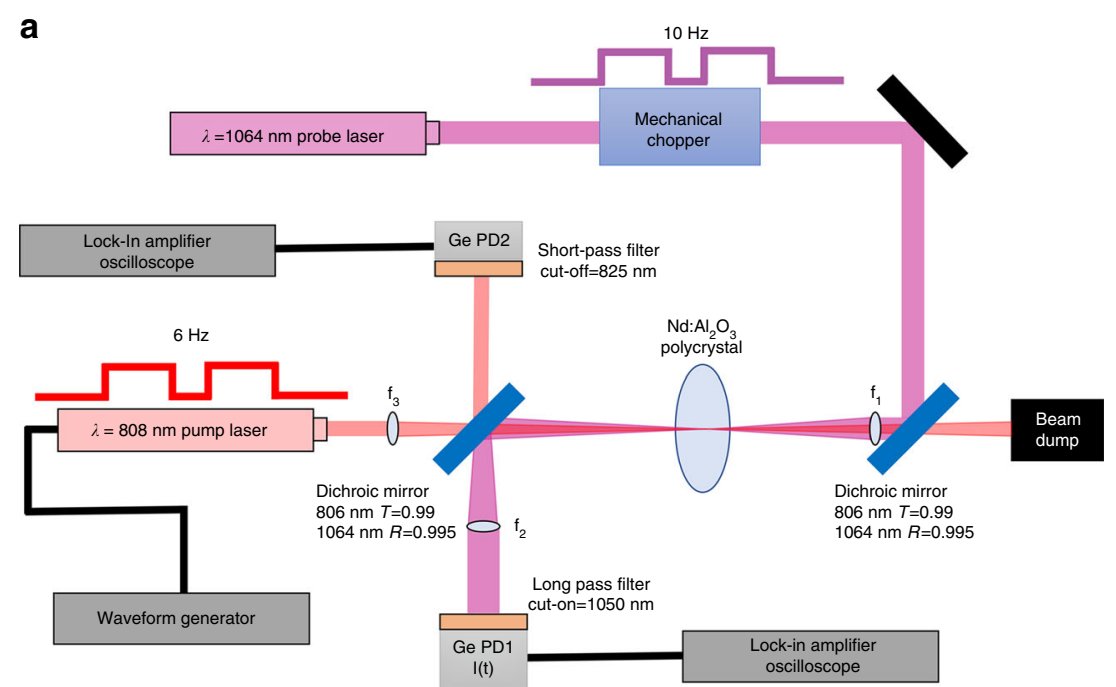

b

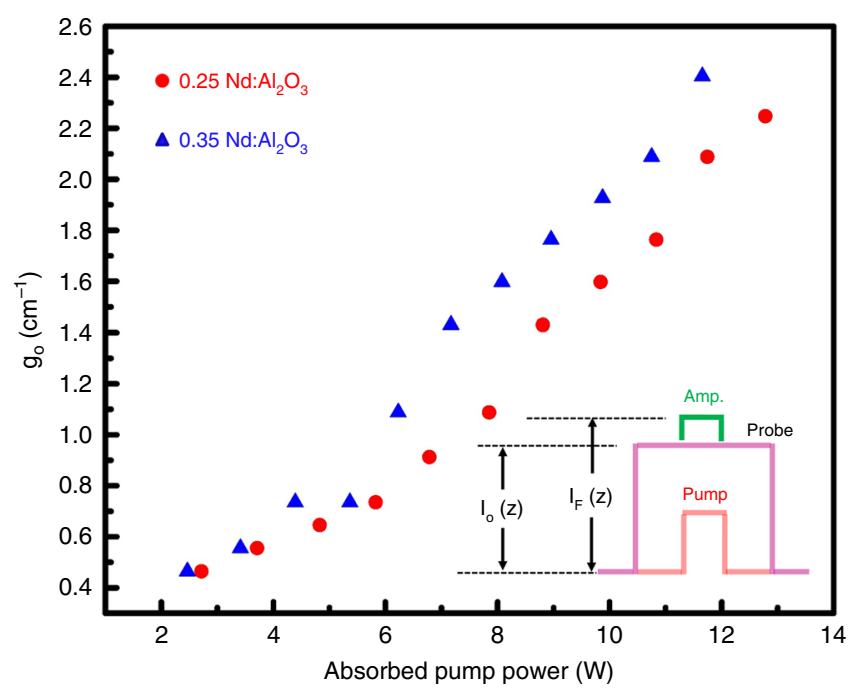

Fig. 5 Demonstration of optical gain. a Schematic of the single-pass measurement set-up. $\mathbf{b}$ Single-pass gain coefficients of the 0.25 at.\% and 0.35 at.\% $\mathrm{Nd}^{3+}: \mathrm{Al}_{2} \mathrm{O}_{3}$ bulk polycrystalline ceramics. The inset schematically shows the relationship between the pump, probe and gain signals and Eq. 3

Figure $5 \mathrm{~b}$ plots the gain coefficients for the 0.25 at.\% and 0.35 at.\% $\mathrm{Nd}^{3+}: \mathrm{Al}_{2} \mathrm{O}_{3}$ ceramics as a function of absorbed pump power. We observe a gain in the transmitted probe laser at absorbed pump powers $>2.25 \mathrm{~W}$ for both materials. The magnitude of $g_{0}$ increases approximately linearly as a function of the absorbed pump power, and in this power range, we do not observe gain saturation. The gain values are as high as $2.27 \mathrm{~cm}^{-1}$ and $2.42 \mathrm{~cm}^{-1}$ for the 0.25 at.\% and 0.35 at.\% $\mathrm{Nd}^{3+}$ concentrations, respectively. These small-signal gain coefficients compare well to values for Nd:YAG $\left(2 \mathrm{~cm}^{-1}\right)^{58}, \mathrm{Nd}$ :Glass $\left(5 \mathrm{~cm}^{-1}\right)^{54}$, Ti: Sapphire $\left(1 \mathrm{~cm}^{-1}\right)^{58}$, and Cr:Sapphire $\left(1 \mathrm{~cm}^{-1}\right)^{58}$. As discussed above, our materials have scattering and absorption losses that are $\sim 1.317 \mathrm{~cm}^{-1}$ after having corrected for reflection loss. It is worth noting that reflection loss can be mitigated using anti-reflection coatings on the ceramic.
These single-pass gain measurements reveal a net positive gain at absorbed pump powers of $>8 \mathrm{~W}$ and $7.2 \mathrm{~W}$ for the 0.25 at.\% and 0.35 at.\% $\mathrm{Nd}: \mathrm{Al}_{2} \mathrm{O}_{3}$, respectively, where $g_{0}$ surpasses the absorption and scattering loss. These measurements explicitly show that the optical quality (transparency, $\tau, \sigma_{\mathrm{Abs}}$, and $\left.\sigma_{\mathrm{Em}}\right)$ of $\mathrm{Nd}^{3+}: \mathrm{Al}_{2} \mathrm{O}_{3}$ bulk ceramics is suitable for amplification and oscillation should optical feedback be introduced, i.e., within a laser cavity employing AR coatings on the gain medium.

We attribute the demonstration of gain to the unique nanostructure of the ceramics. The fine AGS results in an $\mathrm{Al}_{2} \mathrm{O}_{3}$ with a large grain boundary volume, which facilitates the accommodation of the RE without significant concentration quenching. In addition to microstructural control, high heating and cooling rates during CAPAD processing also affect the incorporation of $\mathrm{Nd}^{3+}$ into the 
grain and grain boundary regions without the formation of unwanted secondary phases that lead to poor optical activity.

In summary, we introduce a powder processing route in conjunction with single-step CAPAD reaction/densification to produce transparent bulk polycrystalline $\mathrm{Nd}^{3+}$ : $\mathrm{Al}_{2} \mathrm{O}_{3}$ with $\mathrm{Nd}$ incorporated at concentrations of 0.25 at.\% and 0.35 at.\%. The ceramics have a high transmission at $1064 \mathrm{~nm}$ and display absorption bands at $\lambda=585 \mathrm{~nm}, 748$ $\mathrm{nm}$, and $806 \mathrm{~nm}$, corresponding to transitions from the ${ }^{4} \mathrm{I}_{9 / 2}$ manifold of optically active $\mathrm{Nd}^{3+}$ that result in high peak absorption cross-sections. The PL bandwidth of $\sim 13$ $\mathrm{THz}$ centered at $1064 \mathrm{~nm}$ represents a new record for $\mathrm{Nd}^{3}$ + media, thus permitting the generation of ultra-short pulses. The radiative lifetimes are long and yield a large emission cross-section, which result in an optical gain that is suitable for amplification and lasing. Moreover, the significantly higher $R_{\mathrm{S}} \sim 19,500 \mathrm{~W} / \mathrm{m}$ of $\mathrm{Nd}^{3+}: \mathrm{Al}_{2} \mathrm{O}_{3}$ promises a significantly higher duty-cycle and/or peak-power, making $\mathrm{Nd}^{3+}: \mathrm{Al}_{2} \mathrm{O}_{3}$ a potentially revolutionary gain material. Finally, we note that the nano/microstructural strategies demonstrated here should be applicable to many other oxide and nitride gain systems that were not previously believed to be applicable as laser ceramics and thus represents a new approach to producing gain media.

\section{Materials and methods}

\section{Relations between interionic distance, grain size, and effective length}

An important factor for gain is the average distance between dopant ions, $\tilde{l}$. Dopant concentrations $c$ are usually reported in [at.\%] relative to cations. It is convenient to think about interionic distances using volumetric concentration $c_{\mathrm{vol}}$ [ions $\left./ \mathrm{cm}^{3}\right]$ because $\tilde{l}$ scales with the total number of ions in a volume $V$ such that $\tilde{l} \propto \sqrt[3]{1 / c_{\mathrm{vol}} V}$. Although calculations or measurements of $\tilde{l}$ can be complicated, it is easy to obtain a good estimate of $\sim l$ using a regular pattern of dopants such as a simple cubic cell with RE on each corner with $l$ as a cell length. In this case, $\tilde{l} \sim l=\sqrt[3]{1 / c_{\mathrm{vol}} V}$. We consider laser quality $\mathrm{Nd}$ : YAG as an example, where the typical dopant concentration is $0.5-2$ at.\%. In the $c=2$ at.\% case, $c_{\mathrm{vol}}=$ $7.53 \times 10^{20}$ ions $/ \mathrm{cm}^{3}$ such that $\tilde{l} \sim 1.09 \mathrm{~nm}$.

It is interesting to consider alternate dopant distributions. Consider one grain of gain media approximated as a cube with a global volumetric dopant concentration $c_{\mathrm{vol}}$ [ions $/ \mathrm{cm}^{3}$ ]. The total number of ions $N$ in the volume of that cube is equal to $c_{\mathrm{vol}} d^{3}$, where $d$ is the cube edge length. If all the dopant ions in that cube are placed on the surface (i.e., grain boundary) rather than in the grain volume, one can calculate the effective length (edge length) $d_{\text {eff }}$ necessary to accommodate all the dopants for a given arrangement on the surface of the cube. For simplicity, we can approximate the random arrangement of ions as a regular square unit cell with cell parameter $2 r$ $+l$, where $r$ is ionic radius, and $l$ is the distance between dopant ions. Because there are 6 sides to a cube, $d_{\text {eff }}$ as a function of grain size (edge length) $d$ is

$$
d_{\text {eff }}=\sqrt{\frac{d^{3} c_{\mathrm{vol}}(2 r+l)^{2}}{6}}
$$

A value of $r=1.15 \AA$ for $\mathrm{Nd}$ ions and $l=1 \mathrm{~nm}$ was used for calculations because $1 \mathrm{~nm}$ is a good approximation of $\tilde{l}$, as shown above.

\section{Powder preparation}

Commercially available $\alpha-\mathrm{Al}_{2} \mathrm{O}_{3}$ (99.99\% purity, Taimei Chemicals, Japan) was processed as received (un-doped) and doped with $\mathrm{Nd}_{2} \mathrm{O}_{3}$ (99.99\% purity, Alfa Aesar, USA). The powders were mixed to achieve doping levels $\left(\mathrm{Nd}^{3+}\right.$ : $\mathrm{Al}^{3+}$ ) of 0.25 and 0.35 at.\%. The powders were mixed dry in an alumina mortar by hand for $20 \mathrm{~min}$, which was followed by low-energy ball milling for $12 \mathrm{~h}$ with ultra-high purity (UHP, $99.99 \%$ purity) water as a dispersant. The slurries were sieved and centrifuged for $15 \mathrm{~min}$ at $3400 \mathrm{RPM}$. The powders were dried in a vacuum oven at $70^{\circ} \mathrm{C}$ under a vacuum of $30 \mathrm{~mm} \mathrm{Hg}$ for $12 \mathrm{~h}$. Dried powders were subsequently planetary ball milled with UHP water at 150 RPM for $6 \mathrm{~h}$. Finally, the powders were sieved and dried in air at $120^{\circ} \mathrm{C}$ for $12 \mathrm{~h}$ and kept dry until consolidation.

\section{CAPAD processing}

The powders were densified by $\mathrm{CAPAD}^{47}$ using a graphite die ( $19 \mathrm{~mm}$ outer and $10 \mathrm{~mm}$ inner diameter). This die and plunger set was secured between two $19 \mathrm{~mm}$ punches and placed within a larger graphite die with a 19 $\mathrm{mm}$ inner diameter. The die and powder set were placed into the CAPAD, and a vacuum of $10^{-3}$ Torr was established. The powders were pre-pressed at $106 \mathrm{MPa}$ for 20 min, after which the load was released. An ultimate pressure of $106 \mathrm{MPa}$ with a pressure ramp of $35.33 \mathrm{MPa}$ $\min ^{-1}$ was applied and held constant. In parallel with the application of pressure, the samples were subjected to a heating rate of $\sim 300^{\circ} \mathrm{Cmin}^{-1}$ and a maximum temperature ranging between 700 and $1300^{\circ} \mathrm{C}$ with a hold time of $5 \mathrm{~min}$. The temperature was monitored with a dual wavelength optical pyrometer focused at the die midpoint.

\section{Microstructural characterization}

The powders and densified ceramics were characterized using XRD using $\mathrm{Cu} \mathrm{K \alpha} \alpha_{1}(\lambda=1.54058 \AA)$ radiation on a PANalytical Empyrean Diffractometer (PANalytical, Almelo, The Netherlands) using a step size of $2 \theta=0.005^{\circ}$. Published standards were used for comparison: $\mathrm{Nd}_{2} \mathrm{O}_{3}$ (ICSD\#26867) and $\alpha-\mathrm{Al}_{2} \mathrm{O}_{3}$ (ICSD\#:63647).

The AGS of the densified ceramics were obtained from fracture surfaces by measuring $>300$ grains in multiple 
micrographs at random locations. The fractured surface was sputter coated with a thin film of $\mathrm{Pt} / \mathrm{Pd}$ before examination with a Phillips XL30 field emission scanning electron microscope. EDS mapping was performed using a Titan Themis 399 Scanning-TEM (STEM). The TEM specimen was prepared using a gallium focused ion beam (FIB) and attached to a copper TEM grid using a Pt FIB.

\section{Transmission and photoluminescence measurements}

The samples were polished with diamond suspensions to $0.5 \mu \mathrm{m}$. The final specimen thickness was $0.8 \mathrm{~mm} \pm 0.05$ $\mathrm{mm}$. Transmission spectra were taken on a Varian Cary 500 UV-VIS-IR spectrometer from $300 \mathrm{~nm}$ to $2200 \mathrm{~nm}$ at normal incidence in single-beam mode with a rectangular spot size of $2 \mathrm{~mm}$ by $9 \mathrm{~mm}$, using a scan rate of $0.2 \mathrm{~nm} \mathrm{~s}^{-1}$.

PL was measured on a Horiba Spex Fluorolog 3 Spectrophotometer using an $806 \mathrm{~nm}$ laser diode as the excitation source with a $100 \mathrm{~mW}$ incident power and a spot size of $2 \mathrm{~mm}$. Measurements were taken in front face mode at a $45^{\circ}$ angle of incidence (AOI) on polished samples. Emission scans were taken between $\lambda=1000 \mathrm{~nm}$ and $\lambda=1100 \mathrm{~nm}$ with an integration time of $1 \mathrm{snm}^{-1}$.

\section{Photoluminescence lifetime measurements}

PL lifetimes (pump $=806 \mathrm{~nm}$ ) were obtained using a pulsed tunable laser (Continuum Surelite with optical parametric oscillator). The pulse width was $6 \mathrm{~ns}$, the spot size was $6 \mathrm{~mm}$, and the incident energy was $3 \mathrm{~mJ}$ per pulse. The ceramics were mounted within a Horiba Spex Fluorolog 3 Spectrophotometer, which was coupled to a germanium photodiode and synchronized to a Tektronix TPS2024B oscilloscope. The monochromators were adjusted to observe $1064 \mathrm{~nm}$, with a spectral bandwidth of $1 \mathrm{~nm}$. An optical notch filter centered at $1064 \mathrm{~nm}$ with 8 $\mathrm{nm}$ FWHM transmission band was used to further isolate the pump source. Measurements were taken in front face mode at $45^{\circ}$ AOI. A double-exponential was used to fit data and extract the lifetimes, where $\tau$ is defined as the time required for the intensity to decrease by $1 / e^{27}$.

\section{Single-pass optical gain}

Optical gain was measured using a single-pass arrangement similar to that of Lai et al. ${ }^{57}$, which is shown schematically in Fig. 5b. The samples were held within an aluminum mount atop a 6 -axis kinematic mount that was modified for water cooling, allowing a constant sample temperature of $15^{\circ} \mathrm{C}$ throughout the measurements.

A continuous wave Nd:YAG laser operating at the fundamental wavelength $(\lambda=1064 \mathrm{~nm})$ was used as the probe laser. The collimated probe beam $(\sim 1 \mathrm{~mm}$ diameter) was focused onto the sample with a $100 \mathrm{~mm}$ focal length lens, resulting in a FWHM spot size of $\sim 220 \mu \mathrm{m}$. A fiber coupled Coherent FAP $35 \mathrm{~W}$ laser diode $(\lambda=806 \mathrm{~nm})$ and collimator composed the pumping source. The pump laser was focused onto the sample collinear to, but counter-propagating with respect to the probe using a $35 \mathrm{~mm}$ focal length lens, resulting in a spot size of $\sim 400 \mu \mathrm{m}$. The spot sizes were determined by fitting a Gaussian profile to the probe laser and a top-hat profile to the pump laser from CCD images of the focused beams. The pump beam waist was injected into the arrangement via a dichroic mirror (Thorlabs DMSP1000) with a reflective cut-on wavelength of $1000 \mathrm{~nm}$ at a $45^{\circ} \mathrm{AOI}$. In addition to the factory dielectric coatings, an additional anti-reflective coating for $806 \mathrm{~nm}$ was deposited onto the dichroic optics, which maximized the deliverable pump power onto the test specimens while minimizing stray Fresnel reflections for the pump laser.

The focusing optics for the probe and pump beams were mounted on six-axis kinematic fixtures, allowing a precise spatial alignment of the beams within a single sample interaction volume. The pump and probe beam power were monitored with germanium photodetectors (Thorlabs PDA50B) PD1 and PD2, respectively, which were optically isolated to the desired wavelengths with low and high-pass filters. The pump and probe lasers were operated in quasicontinuous mode using $8 \mathrm{~Hz}$ and $10 \mathrm{~Hz}$ boxcar waveforms, respectively. The fluctuations in the pump and probe laser intensities were recorded using a lock-in amplifier in parallel with an oscilloscope at their respective operating frequencies. This ensures that fluctuations in PD signals are isolated. The photodetectors were calibrated against an optical power meter (Ophir Nova 2).

\section{Acknowledgements}

The funding for this work from the High Energy Laser - Joint Technology Office (HEL-JTO) administered by the Army Research Office is gratefully acknowledged. We gratefully acknowledge Dr. K. Bozhilov from the Center for Advanced Microscopy and Microanalysis (CFAMM) for his help with TEM.

\section{Author contributions}

E.H.P., M.A.D., and Y.K. contributed to the powder processing and characterization. E.H.P. consolidated the gain media. E.H.P., L.F.D., and C.L.H. contributed to the optical spectroscopy and gain measurements. E.H.P. and J.E. G. designed and conceived the experiments and wrote the manuscript. J.E.G. coordinated the project. All authors commented on the manuscript.

Conflict of interest

The authors declare that they have no conflict of interest.

Received: 17 January 2018 Revised: 28 March 2018 Accepted: 15 April 2018 Accepted article preview online: 26 April 2018

Published online: 04 July 2018

\section{References}

1. Wieg, A. T., Kodera, Y., Wang, Z., Dames, C. \& Garay, J. E. Thermomechanical properties of rare-earth-doped AIN for laser gain media: the role of grain boundaries and grain size. Acta. Mater. 86, 148-156 (2015).

2. Kim, W. et al. Ceramic windows and gain media for high-energy lasers. Opt. Eng. 52, 021003 (2012). 
3. Kerse, $\mathrm{C}$. et al. Ablation-cooled material removal with ultrafast bursts of pulses. Nature 537, 84-88 (2016).

4. Liu, R. M. et al. Strong light-matter interactions in single open plasmonic nanocavities at the quantum optics limit. Phys. Rev. Lett. 118, 237401 (2017).

5. Popmintchev, T. et al. Phase matching of high harmonic generation in the soft and hard X-ray regions of the spectrum. Proc. Natl. Acad. Sci. USA 106, 10516-10521 (2009).

6. Di Piazza, A., Müller, C., Hatsagortsyan, K. Z. \& Keitel, C. H. Extremely highintensity laser interactions with fundamental quantum systems. Rev. Mod. Phys. 84, 1177-1228 (2012).

7. Steinmeyer, J. D. et al. Construction of a femtosecond laser microsurgery system. Nat. Protoc. 5, 395-407 (2010).

8. Polini, M. Tuning terahertz lasers via graphene plasmons. Science 351, 229-231 (2016).

9. Ikesue, A. \& Aung, Y. L. Synthesis and performance of advanced ceramic lasers. J. Am. Ceram. Soc. 89, 1936-1944 (2006).

10. Waxler, R. M., Cleek, G. W., Malitson, I. H., Dodge, M. J. \& Hahn, T. A. Optical and mechanical properties of some neodymium-doped laser glasses. J. Res. Natl. Bur. Stand A 75A, 163-174 (1971).

11. Klein, P. H. \& Croft, W. J. Thermal conductivity, diffusivity, and expansion of $\mathrm{Y}_{2} \mathrm{O}_{3}, \mathrm{Y}_{3} \mathrm{~A}_{15} \mathrm{O}_{12}$, and $\mathrm{LaF}_{3}$ in the range $77^{\circ}-300^{\circ} \mathrm{K}$. J. Appl. Phys. 38, 1603-1607 (1967).

12. Ikesue, A. \& Aung, Y. L. Ceramic laser materials. Nat. Photonics 2, 721-727 (2008).

13. Ikesue, A., Aung, Y. L., Taira, T., Kamimura, T. \& Yoshida, K. et al. Progress in ceramic lasers. Annu. Rev. Mater. Res. 36, 397-429 (2006).

14. Ikesue, A. Polycrystalline Nd:YAG ceramics lasers. Opt. Mater. 19, 183-187 (2002).

15. Xu, C. W., Yang, C. D., Zhu, H. Y., Ye, Y. L. \& Duan, Y. M. et al. Diode-pumped Nd: LuAG ceramic laser on $4^{F_{3}} 3 / 2-4^{l} 1_{3 / 2}$ transition. Opt. Mater. 71, 121-124 (2017).

16. Fornasiero, L., Mix, E., Peters, V., Petermann, K. \& Huber, G. Czochralski growth and laser parameters of $\mathrm{RE}^{3+}$-doped $\mathrm{Y}_{2} \mathrm{O}_{3}$ and $\mathrm{Sc}_{2} \mathrm{O}_{3}$. Ceram. Int. 26, 589-592 (2000).

17. Choudhary, A., Beecher, S. J., Dhingra, S., D'Urso, B. \& Parsonage, T. L. et al. 456mW graphene Q-switched Yb:yttria waveguide laser by evanescent-field interaction. Opt. Lett. 40, 1912-1915 (2015).

18. Toci, G., Vannini, M., Ciofini, M., Lapucci, A. \& Pirri, A. et al. $\mathrm{Nd}^{3+}$-doped $\mathrm{Lu}_{2} \mathrm{O}_{3}$ transparent sesquioxide ceramics elaborated by the spark plasma sintering (SPS) method. Part 2: first laser output results and comparison with $\mathrm{Nd}^{3}$ ${ }^{+}$-doped $\mathrm{Lu}_{2} \mathrm{O}_{3}$ and $\mathrm{Nd}^{3+}{ }_{-} \mathrm{Y}_{2} \mathrm{O}_{3}$ ceramics elaborated by a conventional method. Opt. Mater. 41, 12-16 (2015).

19. Penilla, E. H., Kodera, Y. \& Garay, J. E. Blue-green emission in terbium-doped alumina $\left(\mathrm{Tb}: \mathrm{Al}_{2} \mathrm{O}_{3}\right.$ ) transparent ceramics. Adv. Funct. Mater. 23, 6036-6043 (2013).

20. Lupei, V., Lupei, A. \& Ikesue, A. Transparent polycrystalline ceramic laser materials. Opt. Mater. 30, 1781-1786 (2008).

21. Powell, R. W., Ho, C. Y. \& Liley, P. E. Thermal Conductivity of Selected Materials. National Standard Reference Data Series. (U.S. Dept. of Commerce, National Bureau of Standards, Washington, 1966; 1-175.

22. Yao, W. L., Liu, J., Holland, T. B., Huang, L. \& Xiong, Y. H. et al. Grain size dependence of fracture toughness for fine grained alumina. Scr. Mater. $\mathbf{6 5}$, 143-146 (2011).

23. Li W. W., He D. B., Li S. G., Chen W., Chen S. B. et al. Optical and thermal properties of a new ND-doped phosphate laser glass. In Proc. SPIE Pacific Rim Laser Damage 2013: Optical Materials for High Power Lasers. 878629 (SPIE, Shanghai, China, 2013).

24. Koechner, W. Solid-State Laser Engineering (Springer, Berlin, 2006).

25. Maiman, T. H. Stimulated optical radiation in ruby. Nature 187, $493-494$ (1960).

26. Wall, K. F. \& Sanchez, A. Titanium sapphire lasers. Linc. Lab J. 3, 447-462 (1990),

27. Chambers, M. D. \& Clarke, D. R. Doped oxides for high-temperature luminescence and lifetime thermometry. Annu Rev. Mater. Res. 39, 325-359 (2009).

28. Williams, G. R., Bayram, S. B., Rand, S. C., Hinklin, T. \& Laine, R. M. Laser action in strongly scattering rare-earth-metal-doped dielectric nanophosphors. Phys. Rev. A 65, 013807 (2001).

29. Li, B., Williams, G., Rand, S. C., Hinklin, T. \& Laine, R. M. Continuous-wave ultraviolet laser action in strongly scattering Nd-doped Alumina. Opt. Lett. 27, 394-396 (2002).

30. Song, Q., Li, C. R., Li, J. Y., Ding, W. Y. \& Li, S. F. et al. Photoluminescence properties of the $\mathrm{Yb}$ : Er co-doped $\mathrm{Al}_{2} \mathrm{O}_{3}$ thin film fabricated by microwave ECR plasma source enhanced RF magnetron sputtering. Opt. Mater. 28, 1344-1349 (2006).
31. Zhou, B., Xiao, Z. S., Huang, A. P., Yan, L. \& Zhu, F. et al. Effect of Tm-Er concentration ratio on the photoluminescence of $\mathrm{Er}-\mathrm{Tm}: \mathrm{Al}_{2} \mathrm{O}_{3}$ thin films fabricated by pulsed laser deposition. Prog. Nat. Sci. 18, 661-664 (2008).

32. Serna, R., Nuñez-Sanchez, S., Xu, F. \& Afonso, C. N. Enhanced photoluminescence of rare-earth doped films prepared by off-axis pulsed laser deposition. Appl. Surf. Sci. 257, 5204-5207 (2011).

33. Kumaran, R., Webster, S. E., Penson, S., Li, W. \& Tiedje, T. et al. Epitaxial neodymium-doped sapphire films, a new active medium for waveguide lasers. Opt. Lett. 34, 3358-3360 (2009).

34. Kumaran, R., Tiedje, T., Webster, S. E., Penson, S. \& Li, W. Epitaxial Nd-doped a(Al1_X $\mathrm{K}_{\mathrm{G}} \mathrm{ax}$ )203 films on sapphire for solid-state waveguide lasers. Opt. Lett. 35 3793-3795 (2010).

35. Waeselmann, S. H., Heinrich, S., Kränkel, C. \& Huber, G. Lasing of $\mathrm{Nd}^{3+}$ in sapphire. Laser Photonics Rev. 10, 510-516 (2016).

36. Waeselmann S. H., Heinrich S., Kraenkel C., Huber G. Lasing in $\mathrm{Nd}^{3+}$-doped sapphire. Adv. Solid State Lasers. 6-8pp (OSA, Berlin, Germany, 2015).

37. Waeselmann, S. H., Rüter, C. E., Kip, D., Kränkel, C. \& Huber, G. Nd: sapphire channel waveguide laser. Opt. Mater. Express 7, 2361-2367 (2017).

38. Apetz, R. \& Van Bruggen, M. P. B. Transparent alumina: a light-scattering model. J. Am. Ceram. Soc. 86, 480-486 (2003).

39. Penilla, E. H., Hardin, C. L., Kodera, Y., Basun, S. A. \& Evans, D. R. et al. The role of scattering and absorption on the optical properties of birefringent polycrystalline ceramics: modeling and experiments on ruby $\left(\mathrm{Cr}^{\mathrm{A}} \mathrm{Al}_{2} \mathrm{O}_{3}\right)$. J. Appl. Phys. 2, 023106 (2016)

40. Krebs, J. K. \& Happek, U. Yb ${ }^{3+}$ energy levels in a- $\mathrm{Al}_{2} \mathrm{O}_{3}$. J. Lumin. 94-95, 65-68 (2001).

41. Sanamyan, T., Pavlacka, R., Gilde, G. \& Dubinskii, M. Spectroscopic properties of $\mathrm{Er}^{3+}$-doped a-Al $\mathrm{O}_{3}$. Opt. Mater. 35, 821-826 (2013).

42. Pecharromán, C., Mata-Osoro, G., Díaz, L. A., Torrecillas, R. \& Moya, J. S. On the transparency of nanostructured alumina: Rayleigh-Gans model for anisotropic spheres. Opt. Express 17, 6899-6912 (2009).

43. Penilla, E. H., Kodera, Y. \& Garay, J. E. Simultaneous Synthesis and densification of transparent, photoluminescent polycrystalline YAG by current activated pressure assisted densification (CAPAD). Mater. Sci. Eng. B 177, 1178-1187 (2012).

44. Bodišová, K., Klement, R., Galusek, D., Pouchlý, V. \& Drdlík, D. et al. Luminescent rare-earth-doped transparent alumina ceramics. J. Eur. Ceram. Soc. 36, 2975-2980 (2016).

45. Thompson, A. M., Soni, K. K., Chan, H. M., Harmer, M. P. \& Williams, D. B. Dopant distributions in rare-earth-doped alumina. J. Am. Ceram. Soc. 80, 373-376 (1997).

46. Cho, J., Wang, C. M., Chan, H. M., Rickman, J. M. \& Harmer, M. P. A study of grain-boundary structure in rare-earth doped aluminas using an EBSD technique. J. Mater. Sci. 37, 59-64 (2002).

47. Garay, J. E. Current-activated, pressure-assisted densification of materials. Annu Rev. Mater. Res. 40, 445-468 (2010).

48. Cantwell, P. R., Ma, S. L., Bojarski, S. A., Rohrer, G. S. \& Harmer, M. P. Expanding time-temperature-transformation (TTT) diagrams to interfaces: a new approach for grain boundary engineering. Acta. Mater. 106, 78-86 (2016).

49. Bojarski, S. A.., Stuer, M.., Zhao, Z.., Bowen, P.., \& Rohrer, G. S.. Influence of Y and La additions on grain growth and the grain-boundary character distribution of alumina. J. Am. Ceram. Soc. 97, 622-630 (2014).

50. Grasso, S., Yoshida, H., Porwal, H., Sakka, Y. \& Reece, M. Highly transparent aalumina obtained by low cost high pressure SPS. Ceram. Int. 39, 3243-3248 (2013).

51. Yoon, S. J. \& Mackenzie, J. I. Cryogenically cooled $946 \mathrm{~nm}$ Nd: YAG laser. Opt. Express 22, 8069-8075 (2014).

52. Krupke, W. Radiative transition probabilities within the $4 \mathrm{f3}$ ground configuration of Nd: YAG. IEEE J. Quantum Electron 7, 153-159 (1971).

53. Kaminskii, A. A. Laser Crystals: Their Physics and Properties. (Springer, Berlin Heidelberg, 1990)

54. Silfvast, W. T. Laser Fundamentals.. (Cambridge University Press, Cambridge, 2004).

55. Campbell, J. H. \& Suratwala, T. I. Nd-doped phosphate glasses for high-energy/ high-peak-power lasers. J. Non Cryst. Solids 236-264, 318-341 (2000).

56. Aull, B. \& Jenssen, H. Vibronic interactions in $\mathrm{Nd}$ : YAG resulting in nonreciprocity of absorption and stimulated emission cross sections. IEEE J. Quantum Electron 18, 925-930 (1982).

57. Lai S. T. Review of spectroscopic and laser properties of emerald. In Proc. Volume 0622, High Power and Solid State Lasers. 146-150 (SPIE, Los Angeles, CA, 1986).

58. Silfvast W. T. Fundamentals of Photonics. pp1-45 (SPIE, Storrs, CT, 2003). 